\title{
Management of Laryngeal Airway in Reinke's Edema: An Anesthetic Overview
}

\author{
${ }^{1}$ Santosh K Swain, ${ }^{2}$ Mahesh C Sahu
}

\begin{abstract}
Reinke's edema (RE) is a benign polypoidal lesion of the vocal folds. The vocal folds show a white and translucent edema, confined into the superficial lamina propria. The lesions usually affect both vocal folds with fusiform appearance and even mobile during phonation. Hoarseness of voice is the most common clinical presentation in RE. Reinke's edema is often associated with smoking habit, gastroesophageal reflux, and voice abuse. It usually occurs in middle-aged male or postmenopausal women who have a long-term history of smoking. We hereby report a case of a large polypoidal RE who presented with ventilation difficulties during general anesthesia using positive pressure mask ventilation.
\end{abstract}

Keywords: Anesthesia, Laryngeal airway, Reinke's edema.

How to cite this article: Swain SK, Sahu MC. Management of Laryngeal Airway in Reinke's Edema: An Anesthetic Overview. Int J Otorhinolaryngol Clin 2017;9(1):35-37.

\section{Source of support: Nil}

Conflict of interest: None

\section{INTRODUCTION}

Reinke's edema (RE) is a benign disease of the larynx causing diffuse polypoidal degeneration of vocal folds. Usually, it is bilateral and characterized by edematous changes in the superficial layer of lamina propria, leading to balloon-like appearance of vocal folds. It is usually caused by chronic smoking, vocal abuse, and gastroesophageal reflux. Patients of RE usually presents with a rough quality voice and low fundamental frequency. Reinke's edema is named after the anatomist Reinke, ${ }^{1}$ who demonstrated the morphological study of the subepithelial connective tissue of the vocal fold. It is also called as polypoid degeneration, polypoid hypertrophy, or polypoid cordites. Etiopathogenesis of RE is not confirmed till

${ }^{1}$ Professor, ${ }^{2}$ Assistant Professor

${ }^{1}$ Department of ENT, Institute of Medical Sciences and SUM Hospital, Siksha 'O' Anusandhan University, Bhubaneswar Odisha, India

${ }^{2}$ Directorate of Medical Research, Institute of Medical Sciences and SUM Hospital, Siksha 'O' Anusandhan University, Bhubaneswar Odisha, India

Corresponding Author: Santosh K Swain, Professor Department of ENT, Institute of Medical Sciences and SUM Hospital, Siksha 'O' Anusandhan University, K8, Kalinga Nagar Bhubaneswar, Odisha, India, Phone: +91-9556524887, e-mail: santoshvoltaire@yahoo.co.in now. The mechanism for onset and development of RE is still unclear. ${ }^{2}$ Although RE is often the cause for voice changes, it rarely causes airway obstruction and makes a difficult situation for intubation during general anesthesia. We report a case of RE with rare presentation like airway obstruction where management with anesthetic considerations are described in detail.

\section{CASE REPORT}

A 38-year-old man attended the outpatient Department of Otolaryngology for dyspnea since 1 week. He was a known case of RE, diagnosed 1 year back who presented with hoarseness of voice but avoided any treatment. The patient worked as bus conductor and had the habit of chronic smoking with 10 to 15 cigarettes per day since 15 years. His breathing difficulty was more during lying down position while there was no such difficulty during sitting and standing position. He had no history of cough, hemoptysis, or fever. Fiberoptic nasopharyngolaryngoscopy showed bilateral RE, almost obstructing the glottic airway except posterior one-third (Fig. 1). The base of tongue, vallecula, epiglottis, piriform sinus, and postcricoid region were within normal limit. His pulmonary function tests showed normal parameters. Patient was planned for microlaryngeal surgery under general anesthesia. He underwent noninvasive blood pressure monitoring, pulse oximetry, and electrocardiograph. His heart rate was 74/minute, blood pressure was 124/80 mm Hg,

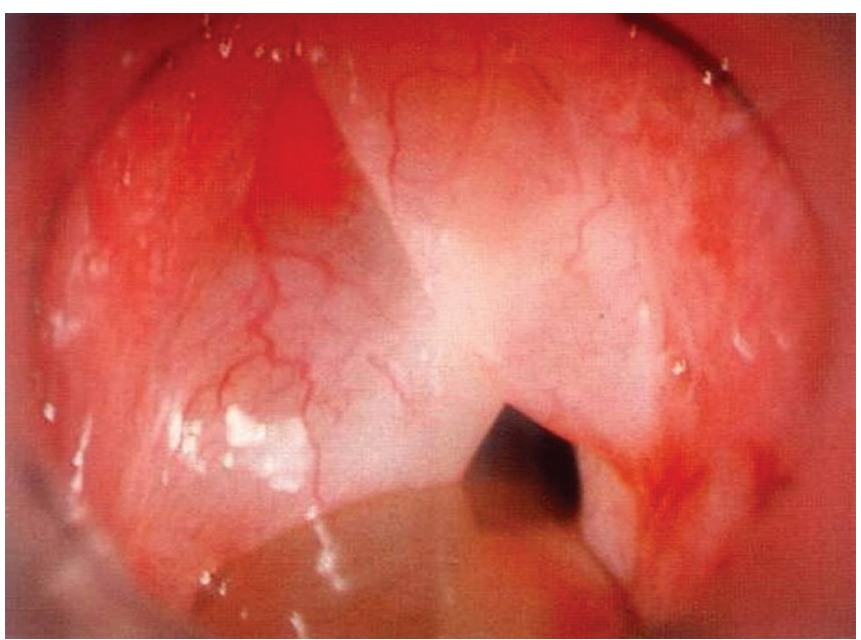

Fig. 1: Postintubated endoscopic picture showing Reinke's edema involving both vocal cords 
and $\mathrm{SpO}_{2}$ was $95 \%$. After preoxygenation for about 3 minutes, preanesthetic induction was accomplished with thiopental $(5 \mathrm{mg} / \mathrm{kg})$ and rocuronium $(1 \mathrm{mg} / \mathrm{kg})$. The intubation was tried with a direct laryngoscope; however, glottic airway was occluded by degenerative polypoidal vocal cords. The patient was planned for awake glidescope-guided tracheal intubation. As the RE was blocking almost the glottic airway, surgical tracheostomy was also planned as the alternative step anticipating difficult airway. He was premedicated with intravenous ranitidine $50 \mathrm{mg}$, ondansetron $4 \mathrm{mg}$, and $0.2 \mathrm{mg}$ glycopyrrolate. The airway was nebulized with $5 \mathrm{~mL}$ of lidocaine (4\%), and oxymetazoline nasal drops were applied before sending the patient to the operation theater. In the operation theater, electrocardiogram, pulse oximetry, and automated blood pressure monitoring were done. Dexmedetomidine infusion was started with $0.5 \mathrm{mg} / \mathrm{kg} / \mathrm{h}$. Then anesthetist retried by a glidescope under direct observation of the lesion. Intubation was done easily. Lesions on bilateral vocal cords were excised with the help of $\mathrm{CO}_{2}$ laser, and surgery was completed without any bleeding at operating site. Extubation was done smoothly and the patient was able to maintain regular breathing pattern and good ventilation. Without any signs of upper airway obstruction, the patient was shifted to recovery room. Patient's arterial blood gas (ABG) in recovery room showed $\mathrm{pH}$ 7.337, $\mathrm{PaCO}_{2} 49.2 \mathrm{~mm} \mathrm{Hg}, \mathrm{PaO}_{2} 95.2 \mathrm{~mm} \mathrm{Hg}$, and absolute base excess $-0.5 \mathrm{mmol} / \mathrm{L}$.

\section{DISCUSSION}

Reinke's edema is a benign lesion of the vocal folds, commonly seen among chronic smokers. It is comparatively common cause of voice disorder among middle-aged population. Gastroesophageal reflux and voice abuse may worsen this pathological condition but do not cause it. $^{3}$ Reinke's edema is an edematous swelling of Reinke's space, the subepithelial matrix of elastin, collagen, and other extracellular proteins that allow high-frequency mucosal vibration. ${ }^{4}$ An increase in vascularity of the lamina propria is noted in RE. ${ }^{5}$ Nicotine components of smoking stimulate angiogenesis, causing increased vascular permeability and therefore, forming subepithelial edema. ${ }^{6}$ Kajek credited for RE with identification of edema at subepithelial compartment of vocal fold, which is superficial to vocal ligament, anteriorly bounded by Broyle's ligament and posteriorly by vocal process of the arytenoids. ${ }^{7}$ Hirano has identified the subepithelial compartment of vocal fold as superficial lamina propria. Zeitels documented this space that underlies the vibratory epithelium of the musculomembranous vocal folds, which can be seen caudally by the inferior arcuate line. Reinke's edema is classified into three stages, depending on the extent of the lesion: Type-I, superficial edema of vocal folds without causing obstruction of the glottic lumen; type-II, lesion involving the posterior portion of the vocal folds; type-III, massive edema of the vocal folds that involves entire length causing a small glottic lumen remaining in the posterior region of the larynx. Our case was showing features of type-III RE. The treatment options for type-III RE is microsurgery, which can be performed by various techniques, such as laser, microdebrider, decortications, and microflap. ${ }^{8}$ Nevertheless, postoperative voice restoration is slow and depends on several factors, especially, the success of the surgical removal of the lesion and smoking cessation. Reinke's edema often presents with hoarseness of voice, but sometimes presents with dyspnea, choking spells, wheezing, and stridor. ${ }^{9}$ Although RE usually progresses slowly over the years, the condition can worsen to the point of causing airway problems. Airway obstruction requires immediate attention. Reinke's edema sometimes being too large, causes airway obstruction, whereas vocal cord poly do not cause airway problems. ${ }^{3}$ Often, airway management is a concern for the anesthesiologist during intubation. Reinke's edema can lead to formation of acquired laryngeal web, which may lead to difficult intubation. ${ }^{10}$ Patients with suspected RE can present with airway problem during anesthesia. ${ }^{11}$ Reinke's edema does not go away on its own and it needs to be identified and addressed properly before its treatment plan. The treatment of RE depends on its severity, glottis airway, and psychological status. Initial treatment of RE includes maintaining good vocal hygiene that consists of cessation of smoking, pharmacological and behavioral treatment for reducing throat clearance, coughing, gastroesophageal reflux, and voice abuse. It is always better to address the factors like gastroesophageal reflux, which usually exacerbates the RE. Voice therapy is helpful for optimal vocal behavior and reduces vocal abuse. Surgical treatment of RE is often elective. The standard surgical technique includes a microflap elevation with removal of polypoidal degeneration and followed by redraping of trimmed epithelium over vocal fold. ${ }^{12}$ Recently, a safe office treatment includes $585 \mathrm{~nm}$ pulse dye laser and the $532 \mathrm{~nm}$ potassium titanyl phosphate in-office photoangiolytic lasers. Even the recent studies of above laser techniques reported safety in RE with photoangiolytic lasers, but a quantitative evaluation for benefit is doubtful. ${ }^{13}$ Edema at subepithelial space and minimal mucosal damage with the microdebrider is new addition to surgical techniques for RE. ${ }^{7}$ If $R E$ is very large, compromising the glottic airway, may need tracheostomy before surgical treatment. Large RE with compromised airway complicates the process of intubation. Multiple attempts for intubation can cause injury to laryngeal mucosa and even arytenoids dislocation. There is also chance of laryngospasm if excessive manipulation 
done to the vocal cords by repeated intubation. For easy intubation, a clear vision of vocal cords is needed. In comparison to direct laryngoscope, a glidescope improves glottis visualization particularly in difficult airway. ${ }^{14}$ Fiberoptic videobronchoscope is also an alternative for beginners and helpful for easy intubation in first attempt and also decreased time for intubation. ${ }^{15}$ The glidescope failure is predicted in case of altered neck anatomy or mass. ${ }^{16}$ In airway management perspective, this patient can have difficult bag mask ventilation. Accordingly, we had prepared for tracheostomy as per the difficult airway. We preferred dexmedetomidine during awake glidescope (fiberoptic videolaryngoscope) as it provides a moderate level of conscious sedation without causing airway distress or hemodynamic instability. ${ }^{17}$ Dexmedetomidine also creates better condition for intubation without causing desaturation. ${ }^{18}$

\section{CONCLUSION}

Reinke's edema is a benign lesion characterized by diffuse polypoid degeneration of vocal folds. Patient is usually presented with a rough vocal quality and low fundamental frequency. It is usually bilateral and commonly seen among adults and smokers. Large polypoidal RE can present with upper airway obstruction, often mask ventilation is difficult after loss of spontaneous ventilation. So sufficient knowledge is required for safe anesthesia. Before inducing the patient, anesthetists must know the patient history and laryngeal airway for safe intubation. It is always better to arrange an alternative like videolaryngoscope for use during intubation. The airway management is an important issue in large RE and should be thoroughly planned to avoid landing up at an unforeseen situation. The pre- and postanesthetic care should be planned individually for better outcome.

\section{REFERENCES}

1. Tillmann B, Rudert H, Schunke M, Werner JA. Morphological studies on the pathogenesis of Reinke's edema. Eur Arch Otorhinolaryngol 1995 Apr;252(8):469-474.

2. Pastuszek P, Krecicki T, Krecicka MZ, Jelen M, Rak J, Krajewska B. Histological and electron microscopic investigation of Reinke's edema. Pol J Pathol 2003 Feb;54(1):61-64.

3. Sulica L. Polyps and Reinke's edema: distinct laryngeal pathologies with different potential for glottic airway obstruction. Anesth Analg 2005 Jun;100(6):1863.
4. Marcotullio D, Magliulo G, Pietrunti S, Suriano M. Exudative laryngeal diseases of Reinke's space: a clinic histopathological framing. J Otolaryngol 2002 Dec;31(6):376-380.

5. Volic SV, Kaplan I, Seiwerth S, Ibrahimpasic T. Extracellular matrix of Reinke's space in some pathological conditions. Acta Otolaryngol 2004 May;124(4):505-508.

6. Berchtold CM, Coughlin A, Kasper Z, Thibeaultet SL. Paracrine potential of fibroblasts exposed to cigarette smoke extract with vascular growth factor induction. Laryngoscope 2013 Sep;123(9):2228-2236.

7. Sant's Anna GD, Mauri M. Use of the microdebrider for Reinke's edema surgery. Laryngoscope 2000 Dec;110(12):2114-2116.

8. Burduk PK, Wierzchowska M, Orzechowska M, Ka mierczak W, Pawlak-Osi ska K. Assessment of voice quality after carbon dioxide laser and microdebrider surgery for Reinke edema. J Voice 2015 Mar;29(2):256-259.

9. Kusunoki T, Fujiwara R, Murata K, Ikeda K. A giant vocal fold polyp causing dyspnea. Ear Nose Throat J 2009 Dec;88(12):1248-1249.

10. Basaranoglu, Erden V, Kokten N, Verim A, Isikci Y, Saitoglu L. Laryngeal web as a result of Reinke's oedema: a cause of difficult tracheal intubation. Br J Anaesth 2006 Mar;96(3):406-407.

11. d'Hulst D, Butterworth J, Dale S, Oaks T, Matthews B. Polypoid hyperplasia of the larynx misdiagnosed as a malpositioned laryngeal mask airway. Anesth Analg 2004 Nov;99(5):1570-1572.

12. Pitman MJ, Lebowitz-Cooper A, Iacob C, Tan M. Effect of the $532 \mathrm{~nm}$ pulsed KTP laser in the treatment of Reinke's edema. Laryngoscope 2102 Dec;122(12):2786-2792.

13. Mouadeb DA, Belafsky PC. In-office laryngeal surgery with the $585 \mathrm{~nm}$ pulsed dye laser (PDL). Otolaryngol Head Neck Surg 2007 Sep;137(3):477-481.

14. Griesdale DE, Liu D, McKinney J, Choi PT. Glidescope videolaryngoscopy versus direct laryngoscopy for endotracheal intubation: a systematic review and meta-analysis. Can J Anaesth 2012 Jan;59(1):41-52.

15. Paolini JB, Donati F, Drolet P. Review article: videolaryngoscopy: another tool for difficult intubation or a new paradigm in airway management? Can J Anaesth 2013 Feb;60(2):184-191.

16. Aziz MF, Healy D, Kheterpal S, Fu RF, Dillman D, Brambrink AM. Routine clinical practice effectiveness of the glidescope in difficult airway management: an analysis of 2,004 glidescope intubations, complications, and failures from two institutions. Anesthesiology 2011 Jan;114(1):34-41.

17. Bergese SD, Khabiri B, Roberts WD, Howie MB, McSweeney TD, Gerhardt MA. Dexmedetomidine for conscious sedation in difficult awake fiberoptic intubation cases. J Clin Anesth 2007 Mar;19(2):141-144.

18. Mondal S, Ghosh S, Bhattacharay S, Choudhury B, Mallick S, Prasad A. Comparison between dexmedetomidine and fentanyl on intubation conditioning during awake fiberoptic bronchoscopy: a randomized double blind prospective study. J Anaesthesiol Clin Pharmacol 2015 Apr-Jun;31(2):212-216. 
